\title{
The impact of teacher engagement in an interactive webinar series on the effectiveness of financial literacy education
}

Citation for published version (APA):

Compen, B., De Witte, K., \& Schelfhout, W. (2021). The impact of teacher engagement in an interactive webinar series on the effectiveness of financial literacy education. British Journal of Educational Technology, 52(1), 411-425. https://doi.org/10.1111/bjet.13013

Document status and date:

Published: 01/01/2021

DOI:

10.1111/bjet.13013

Document Version:

Publisher's PDF, also known as Version of record

\section{Document license:}

Taverne

Please check the document version of this publication:

- A submitted manuscript is the version of the article upon submission and before peer-review. There can be important differences between the submitted version and the official published version of record.

People interested in the research are advised to contact the author for the final version of the publication, or visit the DOI to the publisher's website.

- The final author version and the galley proof are versions of the publication after peer review.

- The final published version features the final layout of the paper including the volume, issue and page numbers.

Link to publication

\footnotetext{
General rights rights.

- You may freely distribute the URL identifying the publication in the public portal. please follow below link for the End User Agreement:

www.umlib.nl/taverne-license

Take down policy

If you believe that this document breaches copyright please contact us at:

repository@maastrichtuniversity.nl

providing details and we will investigate your claim.
}

Copyright and moral rights for the publications made accessible in the public portal are retained by the authors and/or other copyright owners and it is a condition of accessing publications that users recognise and abide by the legal requirements associated with these

- Users may download and print one copy of any publication from the public portal for the purpose of private study or research.

- You may not further distribute the material or use it for any profit-making activity or commercial gain

If the publication is distributed under the terms of Article $25 \mathrm{fa}$ of the Dutch Copyright Act, indicated by the "Taverne" license above, 


\title{
The impact of teacher engagement in an interactive webinar series on the effectiveness of financial literacy education
}

\section{Boukje Compen (D), Kristof De Witte and Wouter Schelfhout}

Boukje Compen is a PhD researcher, affiliated with the Antwerp School of Education of the University of Antwerp, and the Faculty of Business and Economics of KU Leuven. She focuses on the role of the teacher, and teacher professional development, in financial literacy education. Dr Kristof De Witte is a professor at the Faculty of Economics and Business of KU Leuven, and holds the chair in "Effectiveness and Efficiency of Educational Innovations" at United Nations University (UNU-MERIT) at Maastricht University. His research interests comprise education economics, performance evaluation and political economy. Dr Wouter Schelfhout is a professor at the Antwerp School of Education of the University of Antwerp. His research focuses on (a) teacher professional development linked to school policy and capacity building, (b) didactics of economics and financial literacy education. Address for correspondence: Boukje Compen, Antwerp School of Education, Faculty of Social Sciences, University of Antwerp, Sint-Jacobstraat 2,2000, Antwerp, Belgium.Email:boukje.compen@uantwerpen.be

\begin{abstract}
This study examines whether online teacher professional development (OTPD), in the form of an interactive webinar series that encourages collaborative learning, improves student achievement. We conducted a randomised controlled trial with 1102 students, 45 teachers and 30 secondary schools in Flanders, Belgium. As a basis for the study, we developed a digital learning path aimed at improving student scores on financial literacy-a multidimensional key competence recently integrated into the curriculum. We demonstrate that the learning path improves student learning outcomes and that enhanced teacher involvement in this programme does not increase learning outcomes unless the teachers participate in the OTPD initiative. Teacher engagement in the webinar series generated student learning outcomes 0.39 standard deviations higher than those of students whose teachers did not receive this intervention, thus, confirming the effectiveness of the OTPD initiative. This effect was found immediately after programme implementation, and it persisted until at least 6 weeks later. As an underlying mechanism, we observe that engagement in the webinar series enhances teachers' self-efficacy. Classroom observations suggest that engagement increases the frequency of providing students with content-related help.
\end{abstract}

Keywords: Online teacher professional development, Randomised controlled trial, Webinar, Financial literacy

\section{Introduction}

Previous studies have repeatedly demonstrated that teachers differ widely in their value-added in terms of student test scores (Hanushek \& Rivkin, 2010), and that this value-added explains more variation in student achievement than any other school characteristic (Goldhaber, 2002). Effective teaching has been shown to be determined by teacher inputs (eg, teaching experience), as well as by classroom practices that reflect a proactive role on the part of the teacher (eg, monitoring students and providing accurate and timely feedback) (Harris \& Sass, 2011; Kane, Taylor, Tyler \& Wooten, 2011). 


\section{Practitioner Notes}

What is already known about this topic

- Policy makers often rely on teacher professional development (TPD) to improve teacher quality, but rigorous evidence on its effectiveness is limited.

- Collective participation of teachers is a key feature for effective TPD initiatives.

- Online TPD (OTPD) initiatives are suggested as an alternative to traditional initiatives, as they are scalable and reduce opportunity costs.

- Videoconferencing software allows teachers to establish the same type of interactions that occur when teachers meet in person.

What this paper adds

- This paper describes a large-scale randomised controlled trial that examined the potential of OTPD.

- We evaluated an OTPD initiative in the form of an interactive webinar series which encouraged collaborative learning.

- Results indicate that solely when teachers engaged in the webinars, enhanced teacher involvement in the classroom improves student achievement.

- Improved student achievement is observed immediately after implementation of the educational programme, as well as 6 weeks later.

Implications for practice and/or policy

- An interactive webinar series has the potential to improve student achievement, and may be a cost-effective alternative to traditional TPD.

- Considering that the effectiveness of (O)TPD initiatives is often questioned, this result is relevant for policy makers.

While policy makers often rely on teacher professional development (TPD) initiatives to improve the practices of in-service teachers, there has been debate on its actual effectiveness (Garet et al., 2008). Multiple review studies have highlighted a lack of high-quality research (ie, randomised controlled trials) assessing the effectiveness of TPD (Glewwe, Hanushek, Humpage \& Ravina, 2014). Given the high (opportunity) costs of traditional TPD initiatives, online initiatives might provide a cost-effective alternative for improving student learning outcomes. The present study examines the impact of an online teacher professional development (OTPD) intervention on student achievement.

Scholars have identified multiple advantages of OTPD over traditional TPD. Because OTPD does not require meeting at a predefined time or in a predefined space, it allows teachers to learn at their convenience (Duncan-Howell, 2010) and at their own pace (Powell, Diamond, Burchinal \& Koehler, 2010). These options can improve the cost-effectiveness of professional development through economies of scale, while reducing (opportunity) costs relating to teacher time, materials and travel. Worldwide, $89 \%$ of all teachers in lower-secondary education participate in some form of TPD (OECD, 2009). Even a small reduction in perteacher costs could, therefore, have a significant impact on total expenditures. One critical condition for improved cost-effectiveness, however, is that expenditure reductions must not decrease the quality of TPD. Nevertheless, the current evidence on the potential of OTPD to improve student learning, is limited.

The present study evaluates the potential of an OTPD initiative within the context of financial literacy education. Atkinson and Messy (2012, p. 14) describe financial literacy as "a combination 
of awareness, knowledge, skill, attitude and behaviour necessary to make sound financial decisions and ultimately achieve individual financial well-being." This multidimensional concept is interesting to study, as it goes beyond the acquisition of knowledge to integrate the behavioural component. In light of population ageing, increasing complexity in the financial world and high household debt, the ability to make well-informed financial decisions is becoming increasingly important (Aprea et al., 2016; De Beckker, De Witte \& Van Campenhout, 2019a). Significant deficiencies have nevertheless been identified throughout the world and among multiple generations (De Beckker, De Witte \& Van Campenhout, 2020; Finke, Howe \& Huston, 2017; Lusardi \& Mitchell, 2011). Therefore, governments are increasingly integrating financial education into school curricula in order to improve the financial literacy of citizens. While competent teachers are perceived as a prerequisite for effective financial education (Blue, Grootenboer \& Brimble, 2014; Totenhagen et al., 2015), previous studies report a lack of actual and self-perceived competence among teachers (Way \& Holden, 2009; De Beckker, Compen, De Bock \& Schelfhout, 2019), thus, calling for large-scale TPD initiatives.

Given the importance of sustained duration and collective participation of teachers identified in models on the effectiveness of TPD (Smith \& Sivo, 2012), this study evaluates an innovative OTPD initiative, in the form of a webinar series with a strong collaborative-learning component. Surrette and Johnson (2015) conducted a meta-analysis on the ability of OTPD to integrate the critical features for effective TPD as identified by Desimone (2009), and demonstrated that multiple online initiatives were evaluated positively with regard to collaborative-learning possibilities. In the majority of interventions evaluated, teacher interaction occurred using discussion boards or in chat boxes. We follow McConnell, Parker, Eberhardt, Koehler and Lundeberg (2013) in using videoconferencing software, which allows teachers to communicate in real-time, and ensures sustained meeting time while allowing the same type of colleague interaction that occurs in communities of teachers meeting in person (Maher \& Prescott, 2017).

Our research questions is as follows: To what extent can an interactive webinar series enhance the effect of a financial education programme on student financial literacy? To answer this question, we conducted a randomised controlled trial (RCT) with 1102 students, 45 teachers and 30 secondary schools. To evaluate changes in learning outcomes, we administered a pretest (before the educational materials were received), a posttest (immediately after programme implementation) and a follow-up test (6 weeks after programme implementation). Schools were assigned to one of four conditions. Specifically, we compare the learning outcomes of students in the baseline condition, in which students followed a four-hour digital programme on saving and investing, to three other conditions. First, learning outcomes are compared to those of students in a control condition, who had no access to the digital educational materials. Given that financial education programmes, on average, have a significant and positive impact on student financial literacy (Kaiser \& Menkhoff, 2019), we hypothesise that that the current programme benefits student achievement. In the next condition, proactive teacher involvement was encouraged in the programme, which has been shown to be generally beneficial to student achievement (Kane et al., 2011). Therefore, we expect to identify an additional impact of enhanced teacher involvement on student learning. In the final condition, teachers engaged in a three-part webinar series designed to encourage collaborative learning and, eventually, to enhance their (pedagogical) content knowledge. Since previous studies in the financial literacy context suggested a beneficial impact of TPD on student achievement (Harter \& Harter, 2012; Swinton, DeBerry, Scafidi \& Woodard, 2007), our main hypothesis is that the OTPD initiative enhances student financial literacy more than the programme itself. We additionally expect that OTPD participation is more effective than increased teacher involvement alone. Finally, in Section "Underlying mechanisms", we examine 
which factors on the level of the teacher, explain how engagement in the OTPD initiative could eventually benefit student learning.

\section{Methodology}

Research context and the financial education programme

This study was conducted in Flanders, the Dutch-speaking region of Belgium, where the educational system has been undergoing gradual reform since September 2019. Among other curriculum changes, reform efforts have introduced the obligation for secondary schools to provide financial literacy education. At the time of the study, financial literacy education was not yet part of the curriculum.

Two senior economics teachers developed the educational materials in collaboration with the research team. The materials were intended to enhance student knowledge and skills relating to saving and investing. The programme was designed for students aged 13-15 years (ie, eighth and ninth grade), and covered four 50-minute lessons.

The programme was designed as a digital adaptive learning path, with integration of differentiated instruction. In line with Iterbeke, De Witte, Declercq and Schelfhout (2019), we define differentiated instruction as the process of customising instructions to meet the varying learning needs of different students. Specifically, pairs of students followed one of three learning paths, which differed in the cognitive level of the exercises and the amount of feedback provided. Students were assigned to one of the three learning paths according to their scores on a test completed at the start of the programme, estimating their prior knowledge on the topic. The purpose of this differentiated instruction was to make the programme both attainable and motivating for each student.

\section{Data collection}

\section{Student tests}

We adopted a pretest/posttest design to detect changes in student financial literacy resulting from the treatment. The tests were completed during school hours, and administered online. Schools received instructions regarding the timing of the tests and the programme implementation. The posttest was administered at the start of the final hour of the programme, to ensure that all students had sufficient time to finish the test. Six weeks after the programme ended, we asked the schools in the treatment conditions to administer a follow-up test that examined longer-term impact. Schools in the control condition did not receive this test, as it would have required additional time investment without any benefit from the educational material. An overview of the timing is provided in Table S1.

Each test consisted of nine multiple-choice questions, six of which tested the students' knowledge on saving and investing. For example, students were asked to indicate which type of account would yield the highest returns: current accounts or savings accounts. The other three questions assessed the students' behaviours related to saving and investing, as it is critical for individuals to have the skills to actually act upon this knowledge in their daily lives (Yoong, Mihaly, Bauhoff, Rabinovich \& Hung, 2013). For example, one question measured whether students recognised that a particular offer for an online foreign investment fund was "too good to be true." An overview of the pretest items is provided in Table S2.

The pretest also included questions on background characteristics (eg, gender, socio-economic status), as previous research has demonstrated that they influence financial literacy (Lusardi, 2015). Posttest items were comparable to those in the pretest, such that the changes in scores would reflect the learning process. To prevent learning from the test, students received no feedback on their pretest and posttest answers. Similar questions were asked again in the follow-up 
test, after which the students were provided with the correct answers and feedback. Given the possibility that teachers might have continued instruction on financial topics during the period between the posttest and the follow-up test, students were asked to indicate whether this had indeed been the case. We used student identifiers to match the three tests. Online Supplementary File $\mathrm{C}$ discusses indicators of the quality of the test instruments.

Teacher tests

Teacher financial literacy was assessed using six multiple-choice questions examining their knowledge on saving and investing, along with three questions providing insight into their financial behaviour. The knowledge questions were based on the course materials provided in the OTPD initiative. For example, teachers were asked to select from a list the form of saving or investment that was most likely to yield the highest returns. The behavioural questions were derived from a survey measuring financial literacy in adults (OECD, 2016). Questions included, for example, whether the teacher prepared a household budget.

We retrieved a selection of background characteristics that could potentially influence the teachers' financial literacy or teaching behaviour (eg, years of teaching experience, self-efficacy regarding financial topics). In the posttest, teachers again completed a financial literacy test. As part of the fidelity checks, we asked teachers to evaluate the intervention, and to inform us in case they had deviated from the instructions (see Online Supplementary File E). No follow-up test was administered.

Classroom observations

Next to changes in teacher quality (ie, financial literacy), we strive to obtain insight into teaching behaviour. After all, we are interested in revealing how webinar attendance eventually impacts student learning. The quantitative research was, therefore, accompanied by a qualitative exploration. In particular, we visited a random and representative selection of schools for classroom observations (see Online Supplementary File E for a detailed discussion). We developed an observation scheme that, in line with earlier studies evaluating TPD initiatives, served to gain insight into the teacher enactment of the elements covered in the initiative (eg, Baron-Donovan, Wiener, Gross \& Block-Lieb, 2005; Fishman et al., 2013). This implies that the observation scheme contained items related to the specific instructions that teachers in the Active teacher/no OTPD and webinar conditions received regarding the motivating and coaching of students (see Section "Conditions"). In addition, the scheme contained items that allowed us to check fidelity of the general instructions for programme implementation that were received in all treatment conditions. To further examine teacher-student interactions, and primarily instructional support (Allen et al., 2019), the observation scheme also included items reflecting the extent to which teachers were involved with students proceeding along the adaptive learning path, and the number of times that teachers provided help relating to the content of the material. Together, these qualitative aspects should increase our understanding of how the intervention was actually implemented. Finally, to grasp how students experienced the programme, we also observed their behaviour in the classroom. The full observation scheme is provided in Online Supplementary File D.

\section{Conditions}

We randomly assigned each school to one of four conditions. In the "baseline" condition, schools received the standardised educational materials, accompanied by an online teacher manual containing the learning goals, instructions on implementation, a content overview and solutions to all exercises. In this condition, the teacher's role during programme implementation was minimised, as course content was delivered by the digital learning path. 
Schools in the control condition administered the tests simultaneously with schools in the treatment conditions, but they did not receive the educational materials until after administering the posttest. This implies that there was no intervention on either the student or teacher level. Because financial education was not yet part of the curriculum at the time of this study, this condition could be regarded as a pure control condition in which students would not learn about financial topics. Given that teachers in the baseline condition had limited influence during programme implementation, differences observed between the baseline and control condition, solely reflect an effect of the student material.

In the "Active teacher/no OTPD" condition, teachers received no OTPD, but only the teacher manual as included in the baseline condition. The aim of this condition was to examine whether enhanced teacher involvement would increase the impact of the educational materials on student achievement without supportive OTPD. The teachers were asked to develop and implement a motivational phase of approximately 20 minutes to precede the programme (replacing the introductory part in the digital student materials). These teachers were additionally encouraged to monitor and coach students while they proceeded through the material, in addition to organising regular plenary feedback moments. It was emphasised that the aim of these elements was to strengthen the learning path.

The final condition is referred to as the "webinar" condition. A random selection of teachers could participate in an OTPD initiative in the form of a three-part webinar series. The intervention was designed to require a certain time investment on the part of the teachers, in addition to encouraging collaborative learning, as these two aspects are critical to effective professional development (Desimone, 2009; Duncan-Howell, 2010; Smith \& Sivo, 2012).

The OTPD took place before the teachers could start implementing the programme. Each webinar lasted for 1 hour, and teachers were expected to spend 1 hour preparing each webinar using the materials provided in a digital learning environment. The first part of the initiative focused on enhancing teachers' content knowledge on saving and investing, and familiarising them with the setup of the educational materials. In preparation of the webinar, teachers examined the material and tested their own knowledge. In the webinar, the moderator (ie, a senior teacher who had developed the course materials) provided additional instruction, and there was room for teachers' questions. In the second part, teachers' pedagogical knowledge on the encouragement of self-regulated learning was enhanced, specifically with regard to the motivating, activating and coaching of students. As preparation, teachers watched instructional videos on these topics. In the webinar, smaller groups of teachers made assignments related to the videos' content. These were elaborated upon by the moderator. Furthermore, teachers discussed, in groups, the first ideas on how to codesign a motivating phase of approximately 20 minutes, as well as three structured, differentiated feedback moments of approximately 5 minutes each, ultimately intended for actual classroom implementation. These were further developed in between the second and third webinar. In the final session, the groups presented the elements they had designed, and received feedback from the moderator and the other teachers. In addition to the manual that was received in the other treatment conditions, teachers received a guide containing all information required to participate in the OTPD initiative (eg, technical requirements for webinar attendance, and the preparation required for each webinar).

Because the lesson structure was comparable to the one in the Active teacher/no OTPD condition in terms of motivational phase and structured feedback moments, comparing these two conditions can reveal whether professional development is needed in order for enhanced teacher involvement to have a beneficial impact on student achievement.

In Online Supplementary File E, we present fidelity checks for the different conditions, and simultaneously provide examples of how the additional instructions in the Active teacher/no OTPD and Webinar condition were implemented. 


\section{Randomisation procedure}

We recruited schools through an open call on the national financial literacy platform: Wikifin.be. To minimise teacher dropout, we asked all teachers about their interest in participating in the webinar series during the registration phase of the experiment. Schools whose teachers were not interested, were randomly assigned to the baseline, control or Active teacher/no OTPD condition. Schools whose teachers were willing to participate, were randomly assigned either to one of the three conditions without OTPD, or to the webinar condition. Thus, although all four conditions included teachers who were motivated to engage in the initiative, the webinar condition consisted exclusively of these teachers. Although this procedure could have resulted in upper-bound effects, robustness checks suggest that the potential endogeneity issues did not alter the pattern of outcomes (see Online Supplementary File K). Figure S1 provides a schematic overview of the randomisation procedure.

\section{Empirical strategy}

We conducted an ordinary least squares (OLS) regression, in which students' achievement levels were compared between the four conditions. This allowed us to examine the impact of the financial education programme itself, and the potential additional impact of enhanced teacher involvement and the OTPD initiative. We performed the following regression:

$$
Y_{i, s}^{1}=a+\sum_{k=1}^{4} \beta_{k} \text { Treatment }_{i, k}+\gamma Y_{i, s}^{0}+\delta X_{i, s}+\varepsilon_{i, s}
$$

where $Y_{i, s}^{1}$ refers to the posttest score of student $i$ in school $s$ (ie, total, knowledge or behaviour score). Treatment $t_{i, k}$ indicates to which of the $k$ conditions the student's $i$ school $s$ was assigned, and $\beta_{k}$ estimates the effect of being assigned to condition $k$. We consistently control for baseline financial literacy scores $Y_{i}^{0}$, as the change in scores reflects the actual learning process. Control variables at the student and school levels are captured by the vector $X_{i, s}$. The error term, clustered at the school level, is represented by $\varepsilon_{i, s}$.

Note that the estimations for the webinar condition, do not measure the additional impact of attendance of the webinar series in isolation. Rather, we expect the OTPD initiative to also have a reinforcing impact on the effects of the educational material, and the enhanced teacher involvement. The coefficients presented for the webinar condition in the next sections, should therefore be perceived as indicators of the reinforcing impact of the OTPD initiative.

\section{Results}

Sample characteristics

In all, 1102 students from 30 schools completed both the pretest and the posttest. The follow-up test was completed by only 291 students from 11 schools. Descriptive statistics and the number of students and schools per condition are presented in Table S4.

This table additionally displays the average pretest and posttest financial literacy scores. Although students in the control condition tended to have the highest pretest scores (with an unstandardised total score of 4.670 on a scale of 9), students in the control condition were outperformed by those in the webinar condition in the posttest. Additional $t$-test results indicate that the difference between the unstandardised pretest and posttest scores was significantly larger in the webinar condition than in the baseline $(t=-2.804, p \leq .01)$, control $(t=-7.054, p \leq .01)$, and Active teacher/no OTPD $(t=-4.371, p \leq .01)$ conditions. These results might provide an initial indication of the effectiveness of the professional development initiative. Nevertheless, analyses 
using the standardised test scores and including control variables are required to evaluate the actual effect of the intervention. For the small sample with follow-up test results, the change from pretest to follow-up test was larger in the webinar condition than in the baseline $(t=-2.698$, $p \leq .01)$ and Active teacher/no OTPD $(t=-1.707, p \leq .10)$ conditions.

To assess the observed differences between the groups in more detail, we performed a regression analysis on the total pretest score. As indicated by the results reported in Table S5, the difference between the baseline and webinar conditions was significant at the $1 \%$ level. One reason for this imbalance is that we randomised at the school level, which does not necessarily imply that the schools' students were randomly distributed across the four conditions as well. To control for differences between conditions at baseline, we applied the Coarsened Exact Matching procedure as a robustness check (see Online Supplementary File K). Another reason for the imbalance could be the occurrence of attrition. The attrition is discussed in Online Supplementary File I.

\section{OLS estimates}

\section{Posttest}

The estimates from the OLS regressions for the total score, knowledge score and behaviour score are presented in Table 1. Panel A contains the results for the analyses with the posttest score as the outcome variable, and Panel B contains the results for those with the follow-up test score as the outcome variable.

The first column of Panel A shows an estimate of -0.210 for the comparison between the baseline condition and the control condition. As this value is not significant, this implies that students' total financial literacy scores do not seem to benefit from following the financial education programme. The estimate of -0.298 for the Active teacher/no OTPD condition, was not significant either. This indicates that teacher involvement alone does not result in enhanced student scores. In contrast, for the webinar condition, we obtain an estimate with a value of 0.311 . This effect is significant at the $10 \%$ level, and implies that teacher participation in the webinar series enhances financial literacy scores relative to the control condition.

However, given the imbalance in observed characteristics between the control and treatment groups (see Section "Sample characteristics"), it is important to control for the background characteristics. The pattern of results changes slightly when controlling for observed heterogeneity. The control condition, who did not receive any financial education, is outperformed by the baseline condition with 0.29 standard deviations (SD), an effect that is significant at the $10 \%$ level. The estimate for Active teacher/no OTPD, namely -0.269 , is not significant. Focusing on the webinar condition, the estimates show that engagement in the OTPD initiative leads to student scores 0.39 SD significantly higher than in the baseline condition.

Results of the analyses focusing on the knowledge and behaviour scores separately suggest that the baseline condition is primarily performing better than the control condition due to enhanced student performance in the knowledge domain of financial literacy. While the effect of -0.43 $S D$ for the knowledge score is significant when controlling for background characteristics, the control condition performs equally well when the behaviour score is concerned (with an estimate of 0.023). As with the total score, increased teacher involvement alone does not alter the effectiveness of the educational material. Namely, the estimates of -0.203 and -0.271 for the knowledge and behaviour scores, respectively, are not significant. Participation in the webinar series has a beneficial impact on the scores in both domains as a significant estimate of 0.348 is obtained for the knowledge score. The estimate for the behaviour score is 0.304 , and is significant at the $10 \%$ level. 
Table 1: Results OLS regressions

\begin{tabular}{lllllll}
\hline & \multicolumn{2}{c}{ Total score } & \multicolumn{2}{c}{ Knowledge score } & \multicolumn{2}{c}{ Behaviour score } \\
\hline Panel A: Posttest & & & & & & \\
Control & -0.210 & $-0.294^{*}$ & $-0.363^{* *}$ & $-0.426^{* * * *}$ & 0.108 & 0.023 \\
& $(0.154)$ & $(0.152)$ & $(0.144)$ & $(0.126)$ & $(0.120)$ & $(0.140)$ \\
Active teacher/no OTPD & -0.298 & -0.269 & -0.264 & -0.203 & -0.240 & -0.271 \\
& $(0.176)$ & $(0.229)$ & $(0.152)$ & $(0.186)$ & $(0.168)$ & $(0.221)$ \\
Webinar & $0.311^{*}$ & $0.387^{* *}$ & $0.256^{*}$ & $0.348^{* * *}$ & $0.281^{* *}$ & $0.304^{*}$ \\
& $(0.154)$ & $(0.152)$ & $(0.145)$ & $(0.125)$ & $(0.128)$ & $(0.154)$ \\
Controls & & & & & & \\
$R^{2}$ & No & Yes & No & Yes & No & Yes \\
N & 0.193 & 0.233 & 0.170 & 0.217 & 0.122 & 0.145 \\
& 1102 & 1102 & 1102 & 1102 & 1102 & 1102 \\
Control-Active teacher/no OTPD & 0.377 & 0.887 & 0.224 & 0.123 & 0.008 & 0.100 \\
Control一Webinar & 0.000 & 0.000 & 0.000 & 0.000 & 0.008 & 0.002 \\
Active teacher/no OTPD—Webinar & 0.000 & 0.000 & 0.000 & 0.000 & 0.001 & 0.003 \\
& & & & & & \\
Panel B: Follow-up test & & & & & & \\
Active teacher/no OTPD & 0.084 & -0.003 & 0.038 & 0.009 & 0.132 & -0.021 \\
Webinar & $(0.139)$ & $(0.112)$ & $(0.110)$ & $(0.071)$ & $(0.139)$ & $(0.081)$ \\
& $0.533^{* * *}$ & $0.475^{* * *}$ & $0.530^{* *}$ & $0.546^{* * *}$ & $0.346^{* *}$ & 0.180 \\
Controls & $(0.144)$ & $(0.110)$ & $(0.118)$ & $(0.115)$ & $(0.141)$ & $(0.101)$ \\
$R^{2}$ & & & & & & \\
$N$ & No & Yes & No & Yes & No & Yes \\
Active teacher/no OTPD—Webinar & 0.000 & 0.000 & 0.000 & 0.000 & 0.015 & 0.092 \\
\hline & 0.156 & 0.199 & 0.145 & 0.192 & 0.079 & 0.130 \\
\hline
\end{tabular}

Note: Dependent variables represent standardised posttest (Panel A) and follow-up test (Panel B) scores. The baseline condition served as the reference group. The standardised pretest score was included as a control in all regressions. In addition, the following descriptive were controlled for: gender, SES, language, grade, math performance, Dutch performance, motivation, self-efficacy, general education and public. The bottom rows in each panel reflect the $p$ values resulting from $F$-tests comparing the remaining combinations of conditions. The coefficients of all control variables are shown in Table S7. Standard errors clustered at the school level in parentheses.

${ }^{*} p \leq .10 ;{ }^{* *} p \leq .05 ;{ }^{* * *} p \leq .01$.

A variety of robustness checks provide further evidence for our results. These are described in Online Supplementary File K. In addition, we conducted a heterogeneity analysis to demonstrate that the beneficial effect of the webinar series is consistent across students' gender and socio-economic status. This analysis further demonstrates that the webinar series is particularly beneficial to students with a lower than average total pretest score (see Table S10).

Follow-up test

The results for the total, knowledge and behaviour scores obtained on the follow-up test are presented in Panel B of Table 1. Note that no follow-up test was administered to students in the control condition. The pattern of results for the total score is comparable to the short-term impact: the Active teacher/no OTPD estimate of -0.003 (including control variables) is not significant, while the estimate for the webinar condition, with a value of 0.475 (including control variables) 
is significant at the $1 \%$ level. This confirms that encouraging teachers to enrich the digital learning material with an introduction and the provision of feedback is not sufficient to benefit student performance, unless the teachers engage in the OTPD initiative. Results of the robustness checks for the follow-up test are presented in Table S9.

Whereas for the posttest, we observed an additional impact of the webinar series on both the knowledge and behaviour scores, the results for the follow-up test imply that the OTPD initiative primarily benefits the longer-term knowledge scores. Namely, the knowledge score is significantly enhanced with $0.55 S D$, while the estimate of 0.180 , obtained for the behaviour score, is not significant. Comparison of the short-term and long-term findings for knowledge and behaviour implies that the OTPD has a sustained impact on the financial knowledge of students, although its effect on financial behaviour apparently fades over time.

The students' follow-up tests provided an indication of whether teachers had continued to teach about financial topics during the six-week period between the posttest and follow-up test. Results of $t$-tests indicate that, in the webinar condition, more teachers provided additional financial education than was the case in the baseline $(t=5.718, p \leq .01)$ and Active teacher/no OTPD $(t=4.087, p \leq .01)$ conditions. We therefore repeated the analyses on the follow-up test including a dummy variable reflecting additional teaching. The results indicate that controlling for this factor does not affect the pattern of results.

\section{Underlying mechanisms}

This section explores mechanisms that might explain why learning outcomes of students improved when teachers participated in the OTPD initiative. First, we examine whether professional development enhanced the self-efficacy of teachers who attended the webinars, compared to those who did not. Previous research has indicated that teacher self-efficacy is positively correlated with instructional practices and student performance (Settlage, Southerland, Smith \& Ceglie, 2009). To this end, we evaluated the teachers' responses to the statement: "I believe that I have a decent knowledge about anything related to financial education" (Table 2). Teachers in the webinar condition had the highest scores in both the pretest and the posttest. Furthermore, this was the only condition in which self-efficacy increased from the pretest to the posttest. Due to time restrictions,

Table 2: Teacher self-efficacy

\begin{tabular}{llllcc}
\hline & Pretest & Posttest & Difference & $t$ & $N$ \\
\hline Baseline & 5.737 & 5.474 & -0.263 & & 194 \\
Control & $(0.065)$ & $(0.063)$ & $(0.055)$ & & \\
& 5.779 & 5.714 & -0.065 & $-3.453^{* * *}$ & 199 \\
Active teacher/no OTPD & $(0.060)$ & $(0.071)$ & $(0.018)$ & & \\
Webinar & 5.338 & 4.838 & -0.500 & $2.094^{* *}$ & 80 \\
& $(0.073)$ & $(0.072)$ & $(0.115)$ & & \\
& 5.877 & 5.947 & 0.070 & $-5.377^{* * *}$ & 227 \\
\hline
\end{tabular}

Note $<$ del author="Boukje Compen" command="Delete" timestamp="1594885072887" title="Deleted by Boukje Compen on 16-7-2020 09:37:52" class $="$ reU3" $>:</$ del $>$ The average response to the statement: "I believe that I have a decent knowledge about anything related to financial education" (answered on a Likert scale from $1=$ completely disagree to $7=$ completely agree). Standard errors in parentheses. Significance levels correspond to differences relative to the baseline condition, derived from $t$-tests.

${ }^{* *} p \leq .05 ;{ }^{* * *} p \leq .01$. 
no test was administered before the start of the OTPD initiative. The scores of teachers in the webinar condition were thus obtained after webinar attendance, possibly introducing a downward bias in the estimated impact of the mechanism. The result suggests that the OTPD made teachers more self-confident regarding their competences for providing financial education, which has been identified as an important prerequisite for establishing effective learning environments (Holzberger, Philipp \& Kunter, 2013). In contrast, the decrease in self-efficacy observed for the other conditions, might be explained by teachers' inactive involvement in programme implementation (baseline condition), the fact that they had not received the educational material (control condition) or the lack of professional development (Active teacher/no OTPD condition), particularly in combination with the upcoming curriculum reform (McCormick, Ayres \& Beechey, 2006).

Classroom observations provided a second means of identifying how the OTPD initiative benefited student scores. Table 3 presents the descriptive statistics of the observation data. While fifteen classrooms were visited, we include the data of three observations in the baseline condition, and nine in the webinar condition, as we require that the schools completed the posttest. The results should be interpreted with caution, given the small number of observations and imbalance between conditions.

Teachers in the webinar condition tended to spend more time walking around between the student pairs than did those in the baseline condition. In addition, teachers who attended the webinars were actively involved with the students for a greater share of the time than those in the baseline condition. The webinars' focus on enhancing teacher awareness of the importance of providing feedback and continuous coaching might be responsible for such increased teacher involvement. Teachers in the webinar condition were also more likely to help students with the course content. Moreover, in comparison to the baseline condition, these teachers more often clearly helped their students to solve the exercises in the adaptive learning path. Other observed differences related to teacher help were either small or apparently irrelevant to explaining the beneficial effect of webinar attendance on student scores.

Table 3: Classroom observation data

\begin{tabular}{lcc}
\hline & Baseline & Webinar \\
\hline Teacher involvement & & \\
Teacher walks around between the student pairs & 2.333 & 4.286 \\
Teacher is involved with the students (including providing help & 1.667 & 4.375 \\
$\quad$ with the adaptive learning path) & & \\
& & 1.667 \\
Teacher help & 1.000 & 0.444 \\
Trequency of content-wise help to students & 0.333 & 0.889 \\
$\quad$ macher provided help by hinting towards explanation in & 1.000 & 0.333 \\
Teacher provided help by providing additional explanation & 0.000 & \\
Teacher provided help by clearly helping to solve the exercises & & 9
\end{tabular}

Note: Aspects related to the extent of teacher involvement were scored by indicating the share of time per hour in which the behaviour was observed $(1=<20 \%, 2=20-40 \%, 3=40-60 \%, 4=60-80 \%, 5=80-$ $100 \%$ ). Frequency of content-wise help was scored as follows: $0=$ never, $1=<5$ times, $2=5-10$ times, $3=>10$ times. Aspects related to the type of help were scored as a dummy variable $(0=$ type of help not provided, 1 = type of help provided). 


\section{Discussion and conclusion}

This study examined whether OTPD in the form of a webinar series could enhance the impact of a four-hour financial education programme on student financial literacy levels. We conducted a RCT in Flanders, with a total of 1102 students, 45 teachers and 30 secondary schools.

Confirming our hypothesis, we demonstrate that the programme was effective in increasing student learning outcomes. While we expected to find that enhanced teacher involvement would already enhance the effectiveness of the materials, our results indicate that it was beneficial to student performance only in combination with participation in the webinar series that provides insights and ideas related to creating motivational phases and supportive feedback. Providing evidence for our main hypothesis, we find that the financial literacy scores of students whose teachers had participated in the OTPD initiative were 0.39 SD higher than those of students whose teachers had not. This effect was found immediately after programme implementation, and sustained until at least 6 weeks later.

The results demonstrate that the short-term impact of the OTPD on students' financial literacy was driven by increased scores in both the knowledge domain and behaviour domain. We provide evidence that the results could be explained by higher self-efficacy on the part of teachers who had attended the webinar series. Moreover, classroom observations suggested that these teachers provided their students with content-related help more often than their colleagues did. However, with the exception of the webinar condition, we only have limited data on the exact programme implementation, which we consider a limitation of our study. Future studies are therefore encouraged to further examine how the OTPD initiative benefits teaching behaviour, and how this, in turn, benefits student learning.

The long-term results indicate that the impact of the webinars, could be primarily attributed to enhanced knowledge scores. In terms of long-term knowledge retention, increases in knowledge scores were observed in both the posttest and the follow-up test. However, the strong impact of the webinar series on financial behaviour apparently decreased over time. This could be explained by the fact that the digital learning materials strongly encouraged self-regulated learning, which, especially in combination with the provision of feedback by teachers, forms a basis for knowledge retention (Ausubel, 2012; Winne et al., 2006).

The amount of previous RCTs evaluating the impact of TPD on student outcomes, is limited. The meta-analysis by Yoon, Duncan, Lee, Scarloss and Shapley (2007) revealed an average effect size of 0.51 SD for the five RCTs that were included. The data indicated that a minimum of 14 hours of TPD was needed for a significant effect, whereas the initiative in the present study was shown to be effective despite requiring less time investment of teachers. Very few studies conducted RCTs to evaluate the effectiveness of online initiatives on student learning outcomes. A few exceptions, focusing on initiatives in the contexts of "general" literacy and language, showed mixed results: whereas students' abilities in a few examined areas significantly improved due to OTPD, abilities in other areas were not benefited (de Kramer, Masters, O'Dwyer, Dash \& Russell, 2012; Powell et al., 2010). Our finding that financial literacy increases when teachers engage in a webinar series, is therefore a valuable contribution to the existing literature.

With regard to implications for policy and practice, the results demonstrate that an interactive webinar series could be considered as an effective alternative to the more traditional forms of professional development. While it was beyond the scope of this paper to assess cost-effectiveness, future studies could evaluate whether similar OTPD initiatives result in cost reductions. Given that the results indicate that the impact of the webinar series on students' financial behaviour 
tends to diminish over time, future initiatives would benefit from increased insight into how teachers could be educated to have a sustained influence on student behaviour.

\section{Acknowledgements}

We thank Lieve Lammens and Johan Mestdagh for developing the educational materials. We thank Koen Declercq, Danièle Vander Espt, Els Lagrou, Kaat Iterbeke, Joana Elisa Maldonado and LEER workshop participants (Leuven) for their valuable suggestions. This work was supported by the Research Foundation Flanders (FWO) through the "Financial Literacy @ School” programme (grant number S000617N) and is registered in the AEA RCT Registry: AEARCTR-0004447.

\section{Statements on open data, ethics, conflict of interest}

After publication, the data will be made available on the website of the Leuven Economics of Education Research group.

The experiment was setup in close cooperation with the Belgian government institute for Financial Services and Markets Authority (FSMA). We comply with their ethical standards. The student data were collected by administering surveys that examined performance on a test. Test were not shared with teachers, school leaders or parents and were collected, stored and analysed anonymously. Participation in the experiment was, therefore, unlikely to disadvantage students. Similarly, the teacher data were collected, stored and analysed anonymously. Finally, the experiment was registered beforehand on American Economic Association RCT Registry: AEARCTR-0004447.

The authors have no conflicts of interest to declare.

\section{References}

Allen, J., Gregory, A., Mikami, A., Lun, J., Hamre, B., \& Pianta, R. (2019). Observations of effective teacherstudent interactions in secondary school classrooms: Predicting student achievement with the classroom assessment scoring system-Secondary. School Psychology Review, 42(1), 76-98. https://doi. org/10.1080/02796015.2013.12087492

Aprea, C., Wuttke, E., Breuer, K., Koh, N. K., Davies, P., Greimel-Fuhrmann, B., \& Lopus, J. S. (2016). International handbook of financial literacy. Singapore: Springer.

Atkinson, A., \& Messy, F. (2012). Measuring financial literacy: Results of the OECD/International Network on Financial Education (INFE) pilot study. Paris, France: OECD Publishing.

Ausubel, D. P. (2012). The acquisition and retention of knowledge: A cognitive view. Dordrecht, the Netherlands: Springer Science \& Business Media.

Baron-Donovan, C., Wiener, R. L., Gross, K., \& Block-Lieb, S. (2005). Financial literacy teacher training: A multiple-measure evaluation. Journal of Financial Counseling and Planning, 16(2), 63-75.

Blue, L., Grootenboer, P., \& Brimble, M. (2014). Financial literacy education in the curriculum: Making the grade or missing the mark? International Review of Economics Education, 16, 51-62. https://doi. org/10.1016/j.iree.2014.07.005

De Beckker, K., Compen, B., De Bock, D., \& Schelfhout, W. (2019). The capabilities of secondary school teachers to provide financial education. Citizenship, Social and Economics Education, 18(2), 66-81. https:// doi.org/10.1177/2047173419850152.

De Beckker, K., De Witte, K., \& Van Campenhout, G. (2019a). Identifying financially illiterate groups: An international comparison. International Journal of Consumer Studies, 43(5), 490-501. https://doi. org/10.1111/ijcs.12534 
De Beckker, K., De Witte, K., \& Van Campenhout, G. (2020). The role of national culture in financial literacy: Cross-country evidence. The Journal of Consumer Affairs. https://doi.org/10.1111/joca.12306.

de Kramer, R. M., Masters, J., O’Dwyer, L. M., Dash, S., \& Russell, M. (2012). Relationship of online teacher professional development to seventh-grade teachers' and students' knowledge and practices in English language arts. The Teacher Educator, 47(3), 236-259. https://doi.org/10.1080/08878730.2012.685795

Desimone, L. M. (2009). Improving impact studies of teachers' professional development: Toward better conceptualizations and measures. Educational Researcher, 38(3), 181-199. https://doi.org/10.3102/00131 89X08331140

Duncan-Howell, J. (2010). Teachers making connections: Online communities as a source of professional learning. British Journal of Educational Technology, 41(2), 324-340. https://doi. org/10.1111/j.1467-8535.2009.00953.x

Finke, M. S., Howe, J. S., \& Huston, S. J. (2017). Old age and the decline in financial literacy. Management Science, 63(1), 213-230. https://doi.org/10.1287/mnsc.2015.2293

Fishman, B., Konstantopoulos, S., Kubitskey, B. W., Vath, R., Park, G., Johnson, H., \& Edelson, D. C. (2013). Comparing the impact of online and face-to-face professional development in the context of curriculum implementation. Journal of Teacher Education, 64(5), 426-438. https://doi.org/10.1177/0022487113 494413

Garet, M. S., Cronen, S., Eaton, M., Kurki, A., Ludwig, M., Jones, W., ... Silverberg, M. (2008). The impact of two professional development interventions on early reading instruction and achievement. Washington, DC: National Center for Education Evaluation and Regional Assistance, Institute of Education Sciences, U.S. Department of Education.

Glewwe, P. W., Hanushek, E. A., Humpage, S. D., \& Ravina, R. (2014). School resources and educational outcomes in developing countries: A review of the literature from 1990 to 2010. In P. W. Glewwe (Ed.), Education policy in developing countries (pp. 13-65). Chicago, IL: The University of Chicago Press.

Goldhaber, D. (2002). The mistery of good teaching. Education Next, 2(1), 1-8.

Hanushek, E. A., \& Rivkin, S. G. (2010). Generalizations about using value-added measures of teacher quality. American Economic Review, 100(2), 1051-1078. https://doi.org/10.1257/aer.100.2.267

Harris, D. N., \& Sass, T. R. (2011). Teacher training, teacher quality and student achievement. Journal of Public Economics, 95(7-8), 798-812. https://doi.org/10.1016/j.jpubeco.2010.11.009

Harter, C. L., \& Harter, J. F. R. (2012). Does a graduate course in personal finance for teachers lead to higher student financial literacy than a teacher workshop? Journal of Consumer Education, 29, 35-46.

Holzberger, D., Philipp, A., \& Kunter, M. (2013). How teachers' self-efficacy is related to instructional quality: A longitudinal analysis. Journal of Educational Psychology, 105(3), 774-786. https://doi.org/10.1037/ a0032198

Iterbeke, K., De Witte, K., Declercq, K., \& Schelfhout, W. (2019). The effect of ability matching and differentiated instruction in financial literacy education. Evidence from two randomised control trials. Economics of Education Review. https://doi.org/10.1016/j.econedurev.2019.101949.

Kaiser, T., \& Menkhoff, L. (2019). Financial education in schools: A meta-analysis of experimental studies. Economics of Education Review. https://doi.org/10.1016/j.econedurev.2019.101930.

Kane, T. J., Taylor, E. S., Tyler, J. H., \& Wooten, A. L. (2011). Identifying effective classroom practices using student achievement data. The Journal of Human Resources, 46(3), 587-613. https://doi.org/10.3368/ jhr.46.3.587

Lusardi, A. (2015). Financial literacy skills for the 21st century: Evidence from PISA. The Journal of Consumer Affairs, 49(3), 639-59. https://doi.org/10.1111/joca.12099

Lusardi, A., \& Mitchell, O. S. (2011). Financial literacy around the world: An overview. Journal of Pension Economics \& Finance, 10(4), 497-508. https://doi.org/10.1017/S1474747211000448

Maher, D., \& Prescott, A. (2017). Professional development for rural and remote teachers using video conferencing. Asia-Pacific Journal of Teacher Education, 45, 520-538. https://doi.org/10.1080/13598 66X.2017.1296930

McConnell, T. J., Parker, J. M., Eberhardt, J., Koehler, M. J., \& Lundeberg, M. A. (2013). Virtual professional learning communities: Teachers' perceptions of virtual versus face-to-face professional development. Journal of Science Education and Technology, 22(3), 267-277. https://doi.org/10.1007/s1095 6-012-9391-y 
McCormick, J., Ayres, P. L., \& Beechey, B. (2006). Teaching self-efficacy, stress and coping in a major curriculum reform: Applying theory to context. Journal of Educational Administration, 44(1), 53-70. https://doi. org/10.1108/09578230610642656

OECD. (2009). Creating effective teaching and learning environments. First results from TALIS, Paris, France: OECD.

OECD. (2016). OECD/INFE international survey of adult financial literacy competencies. Paris, France: OECD.

Powell, D. R., Diamond, K. E., Burchinal, M. R., \& Koehler, M. J. (2010). Effects of an early literacy professional development intervention on head start teachers and children. Journal of Educational Psychology, 102(2), 299-312. https://doi.org/10.1037/a0017763

Settlage, J., Southerland, S. A., Smith, L. K., \& Ceglie, R. (2009). Constructing a doubt-free teaching self: Self-efficacy, teacher identity, and science instruction within diverse settings. Journal of Research in Science Teaching, 46(1), 101-125. https://doi.org/10.1002/tea.20268

Smith, J. A., \& Sivo, S. A. (2012). Predicting continued use of online teacher professional development and the influence of social presence and sociability. British Journal of Educational Technology, 43(6), 871-882. https://doi.org/10.1111/j.1467-8535.2011.01223.x

Surrette, T. N., \& Johnson, C. C. (2015). Assessing the ability of an online environment to facilitate the critical features of teacher professional development. School Science and Mathematics, 115(6), 260-270. https://doi.org/10.1111/ssm.12132

Swinton, J., DeBerry, T., Scafidi, B., \& Woodard, H. (2007). The impact of financial education workshops for teachers on students' economic achievement. The Journal of Consumer Education, 24, 63-77.

Totenhagen, C. J., Casper, D. M., Faber, K. M., Bosch, L. A., Wiggs, C. B., \& Borden, L. M. (2015). Youth financial literacy: A review of key considerations and promising delivery methods. Journal of Family and Economic Issues, 36(2), 167-191. https://doi.org/10.1007/s10834-014-9397-0

Way, W. L., \& Holden, K. (2009). 2009 Outstanding AFCPE conference paper: Teachers' background and capacity to teach personal finance: Results of a national study. Journal of Financial Counseling and Planning, $20(2), 64-78$.

Winne, P. H., Nesbit, J. C., Kumar, V., Hadwin, A. F., Lajoie, S. P., Azevedo, R., \& Perry, N. E. (2006). Supporting self-regulated learning with gStudy software: The learning kit project. Technology Instruction Cognition and Learning, 3, 105-113.

Yoon, K. S., Duncan, T., Lee, S. W., Scarloss, B., \& Shapley, K. L. (2007). Reviewing the evidence on how teacher professional development affects student achievement. Washington, DC: Institute of Education Sciences (IES).

Yoong, J., Mihaly, K., Bauhoff, S., Rabinovich, L., \& Hung, A. (2013). A toolkit for the evaluation of financial capability programs in low- and middle-income countries. Washington, DC: International Bank for Reconstruction and Development/The World Bank.

\section{Supporting Information}

Additional supporting information may be found online in the Supporting Information section at the end of the article. 